\title{
Structural Behaviour of Steel Frame in Building Fire
}

\section{K. NAKAMURA}

Building Research Institute

Ministry of Construction, Japan

\section{K. SHINODA}

Gifu Prefectural Government, Japan

\section{HIROTA}

Shimizu Construction Co. Ltd., Japan

\section{K. KAWAGOE}

Center for Fire Science and Technology

Science University of Tokyo, Japan

\section{ABSTRACT}

More than fifty experiments were made with model steel frames of two dimensional two story and of three dimensional three story. in which girders or a column or both a girder and columns were heated by electric furnaces under a constant heating rate. These experiments made it possible to analyze thermal stress within the steel frame theoretically. Large thermal stress appeared in the frame corresponding to the "binding modulus" of the frame. The structure was more influenced by the thermal expansion generated by the heated girder than by that of the heated column in the elastic region. In some cases the buckling of heated girder or column occurred.

And also heated tests of columns in a six story full scale steel frame were made. The local buckling of column occurred from which the whole structure was influenced.

keywords: Thermal stress, Fire resistance, Building fire, Steel frame, Buckling

\section{INTRODUCTION}

As often pointed out, the accepted mechod of fire design based on standard fire resistance tests of structural elements has many problems. If fire design is going to keep pace with modern trends in other engineering design disciplines, we must appraise structural fire safety by an analytical structural fire engineering design method based on the structural behavior of the complete steel frames in fire. Recently, several such methods have been proposed. [1,2] These methods are important to the estiablishment of the analytical fire engineering design method. To investigate the applicability of these methods, a series of experimental studies based on heat tests of steel frames were started in 1981. These tests were:

1981: 22 Heat tests of a girder in a two dimensional two story model stee 1 frame[3] 
1982: 16 Heat tests of girders in a three dimensional three story steel frame [4]

1983: 13 Heat tests of girders or a column or both a girder and columns in the same frame[5]

1984: 2 additional tests of 1983 and 4 heat tests of a column in a full scale six story steel frame.

This paper summarizes the experimental results of these heat tests.

\section{EXPERIMENTS OF MODEL STEEL FRAME}

\subsection{Experimental Set-up}

(1) Model steel frame

Fig. 1 shows the two-dimensional model steel frame tested in 1981. Many interesting results were obtained to use this frame[3], but the test results showed us that the ratio of girder and column length was not suitable for model tests and the effect of the distortion of frame could not be eliminated. Then the new threedimensional model steel frame was designed as shown in Figs. 2-1 and 2-2. The columns and girders were connected by high-tension bolts so that it is possible to change the element.

(2) Electric furnace

Box shaped furnaces, composed of thermal insulation board in which electric heat panels were set were used. Fig. 3 shows examples of the temperature distribution in the girder and column. (3) Loading set-up

The loading set-up was composed of hydraulic jacks and a loading frame, as shown in Fig.2. The compressive loads were applied on the top of columns by hydraulic jacks.

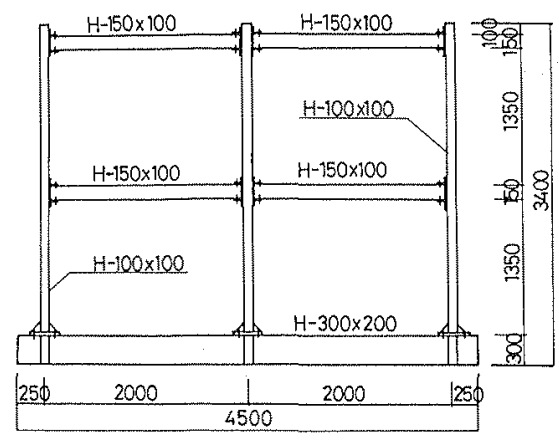

Fig. 1 Two dimensional model

Fig.2-1 Three dimensional model 


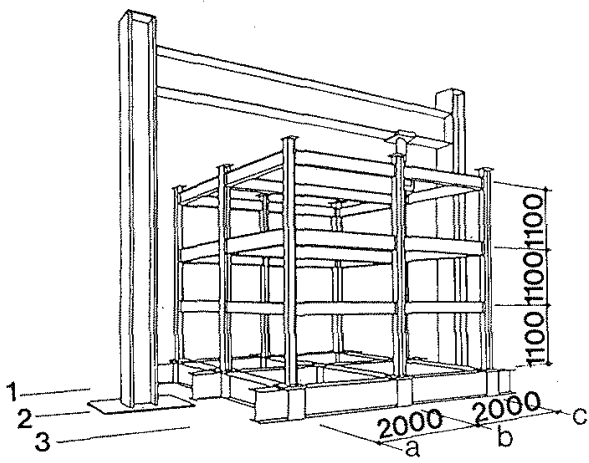

Fig.2-2 Three dimensional model
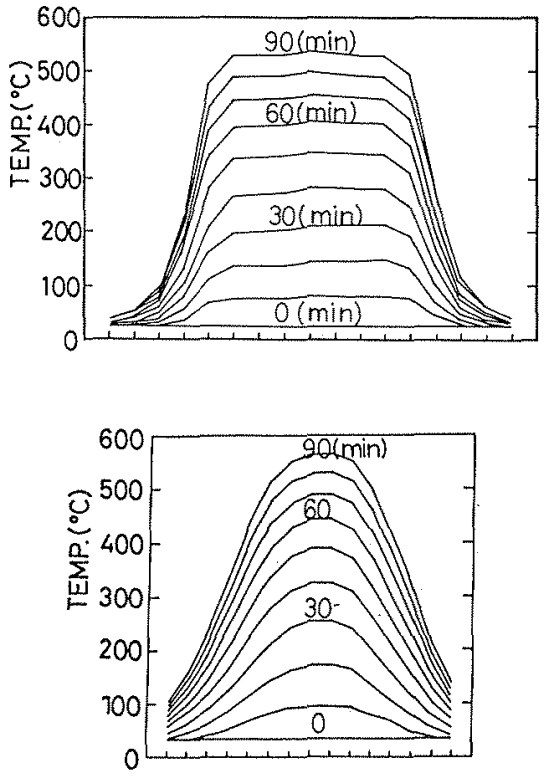

Fig. 3 Temperature distribution (upper: girder, lower: column)

\subsection{Experimental Procedure}

\section{(1) Experimental mode 1}

Table 1 shows the types of frame and the positions of electric furnaces for each experiment in the series of 1982, and Table 2 shows one of in 1983.

(2) Experimental measurements

(a) Temperature: Room temperature, non-heated steel frame temperature, temperature of heated girder and column, and the ambient temperature in the furnace were measured by thermocouples(CA). (b)Strain: The compressive and tensile strains of the steel members were measured by strain gauges which were attached on the surface of steel members. They were located at the top and bottom of the columns and the near positions of both end of the girders. (c)Displacements: The horizontal and vertical displacements of the column-girder connection points were measured by the dial gauges.

\subsection{Experimental Results}

The distribution of bending moment inside frame were calculated from the measured values of strain gauges and the deformation of frame were obtained from horizontal and vertical displacements measured at the column-girder connection points. The examples of their diagrams are shown in Figs. 4 and 6 . 
Table 1 Experimental model of 1982

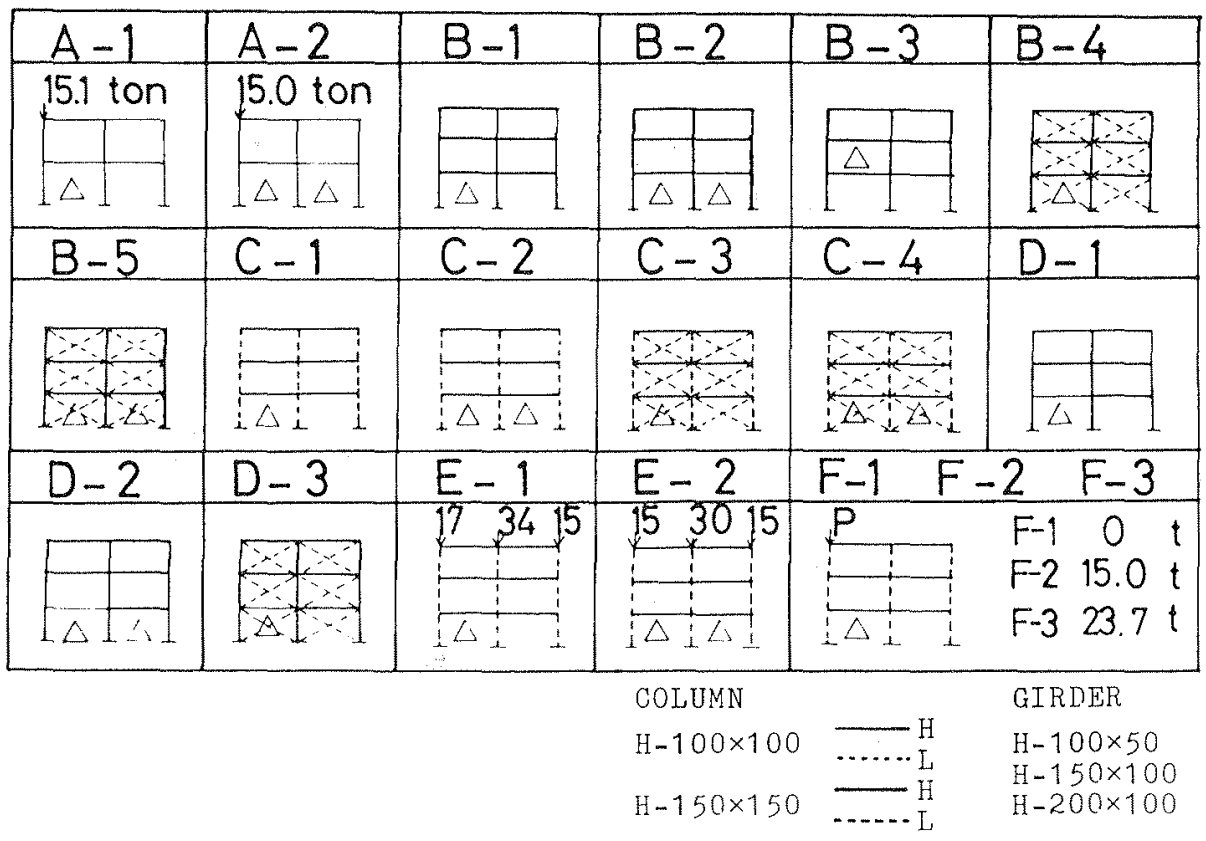

Table 2 Experimental model of 1983

Type A

TEST FRAME HEATED LOAD COLUMN GIRDER NO. TYPE MEMBER P

\begin{tabular}{|c|c|c|c|c|c|}
\hline$G-1$ & $A$ & 1 & & B & A \\
\hline$G-2$ & $B$ & 1 & & B & A \\
\hline $\mathrm{H}-1$ & $\mathrm{~A}$ & 2 & & $\mathrm{~B}$ & $A$ \\
\hline $\mathrm{H}-2$ & B & 2 & & B & A \\
\hline $\mathrm{H}-3$ & $A$ & 3 & & B & A \\
\hline $\mathrm{H}-4$ & A & 4 & & $\mathrm{~B}$ & A \\
\hline $\mathrm{H}-5$ & $\mathrm{C}$ & 1 & $38.95 t$ & B & A \\
\hline$I-1$ & A & $1,2,3$ & & $B$ & A \\
\hline$I-2$ & $\mathrm{~B}$ & $1,2,3$ & & B & A \\
\hline$I-3$ & A & 1,2 & & B & A \\
\hline$J-1$ & A & 1 & $28.29 t$ & $\mathrm{~A}$ & A \\
\hline$J-2$ & B & 1 & $43.36 t$ & $\mathrm{~A}$ & B \\
\hline$J-3$ & B & 1 & $31.50 t$ & $\mathrm{~A}$ & A \\
\hline
\end{tabular}
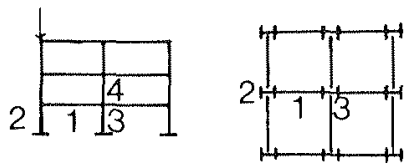

Type B

\section{Column}

(A) $\mathrm{H}-100 \times 100$ (Low Stiffness)

(B) $\mathrm{H}-150 \times 150$ (High Stiffness)

\section{Girder}

(A) $\mathrm{H}-200 \times 200$

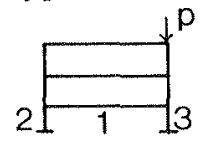

Type $\mathrm{C}$

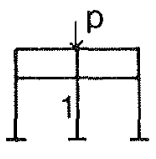

(B) $\mathrm{H}-250 \times 125$
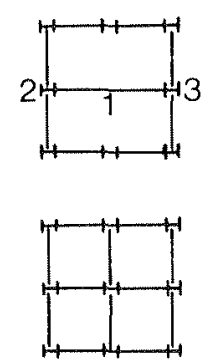

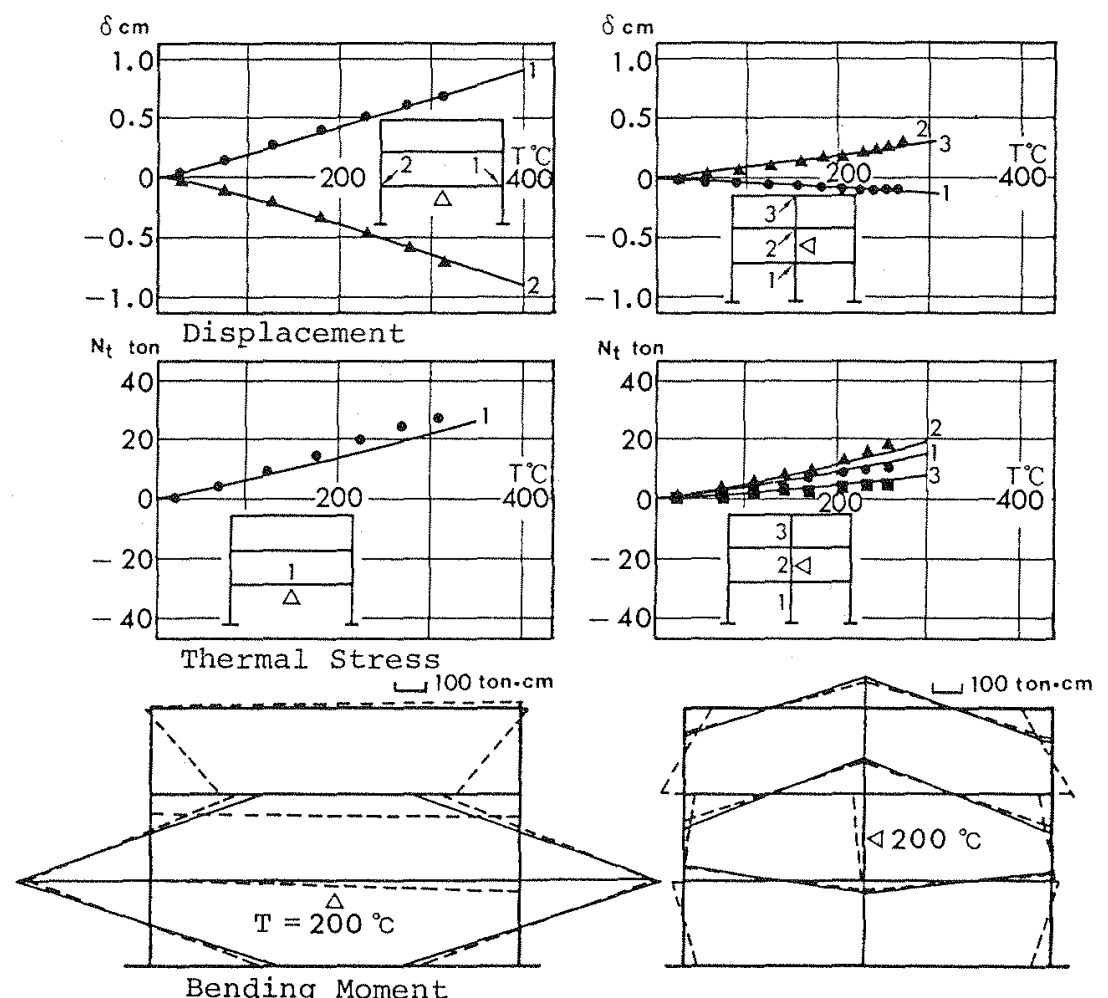

$\triangle$ Heated Member

- $\|$-..- Experimental Value

- Theoretical Value

Fig. 4 Theoretical and experimental Values of displacement, thermal stress and bending moment

\section{RESULTS AND DISCUSSION}

\subsection{Heat Tests of Column or Girder}

Fig. 4 shows some examples of the theoretical and experimental values of displacement, thermal stress and bending moment when a girder or a column was heated. The theoretical values were obtained from the method of Saito[6-8] based on the idea of coefficient of stiffness for expansion as shown in Appendix. T in Fig. 4 means the mean temperature rise of heated stee 1 member. The theoretical values agree with the experimental ones very well in the elastic region. [4]

The buckling of heated girder occurred in the case of $D-1,2$ and 3 in Table 7. The comparison between experimental and theoretical values of the buckling stress is shown in Fig. 5 . The sum of the thermal stress increases as the temperature rise increases and eventually reaches the theoretical values of the buckling stress which decreases as the temperature rise. 


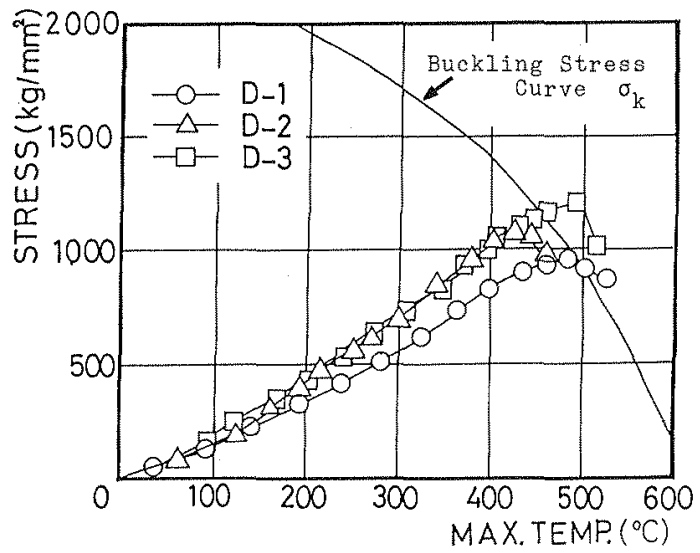

Fig. 5 Comparison between experimental and theoretical values of buckling stress

\subsection{Heat Tests of Both Columns and a Girder}

The correlations between the theoretical values and the experimental ones of deformation and bending moment when columns and a girder were heated are shown in Fig.6. In this case, the theoretical values were obtained from a more sophisticated method named "direct stiffness method". [5] From Fig.6, it is seen that the theoretical values agree with the experimental values and that the thermal stresses resulted from the thermal expansion of the heated girder and the restriction of heated members imposed by the remainder of the frame. The results also show that the structure is more influenced by the thermal stress induced by a heated girder than that of heated columns in the elastic region.

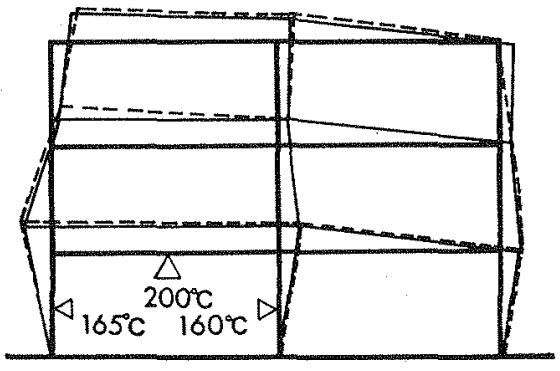

Deformation
$-2 \mathrm{~mm}$

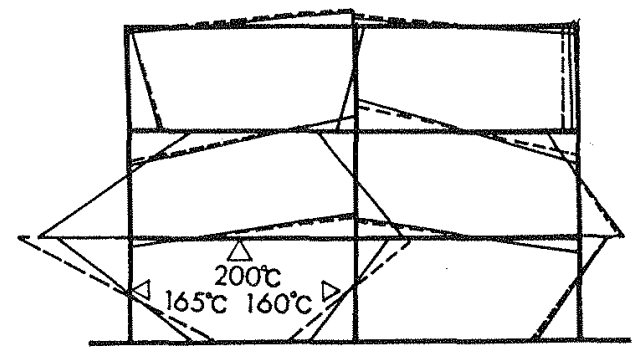

Bending Moment $-100 \mathrm{t} \cdot \mathrm{cm}$

--- Experimental Value Theoretical value

Fig. 6 Correlation between theoretical and experimental value of deformation and bending moment 


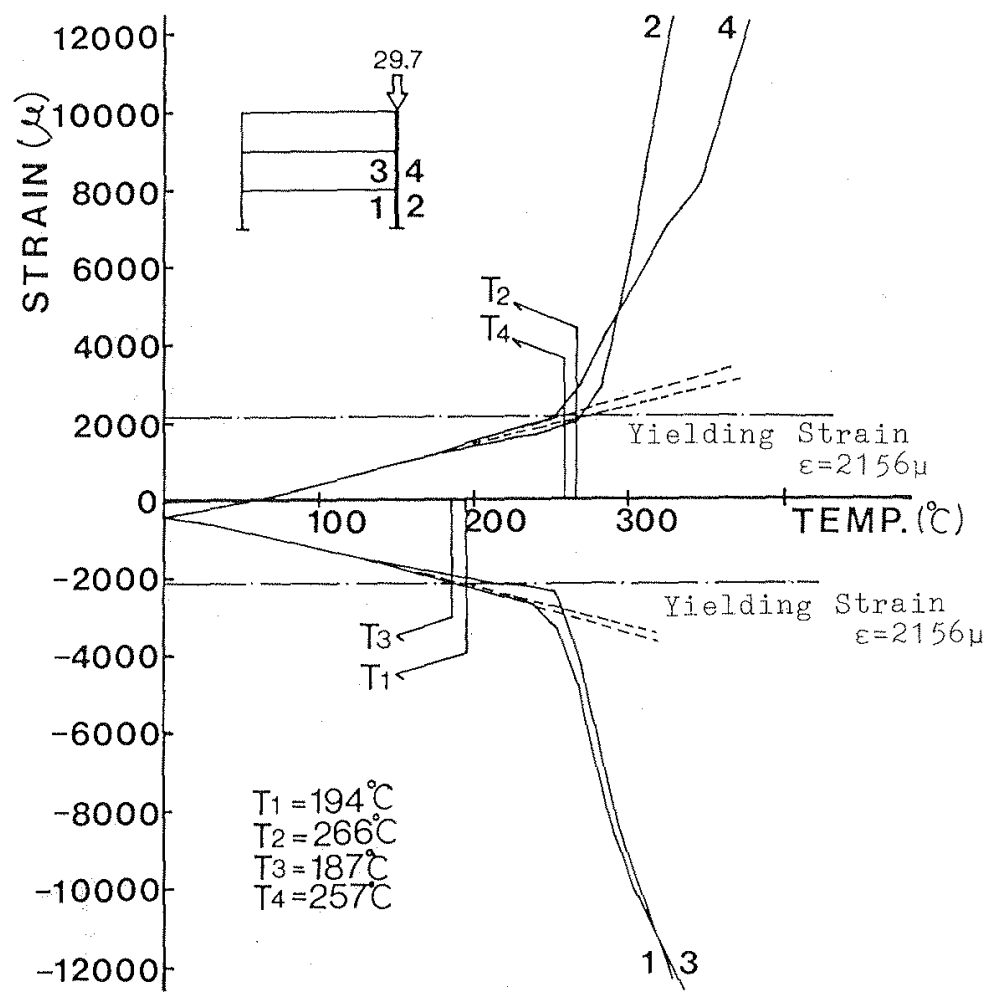

Fig. 7 Relation between measured strain of column and estimated mean temperature of heated girder

\subsection{Yield of Restraining Column}

Damage to the restraining columns was different from that of the heated members. This was demonstrated in the experiment in 1984 as shown in Fig.7. On the basis of measurement of strain, it could be expected that the column would yield at their end. Fig. 7 shows the relation between the measured strain of the column and the estimated mean temperature of heated girder. The following facts could be deduced; the bending strain in the column increases linearly as the increase of temperature of the heated girder, and the strain increases rapidly after the yielding occurs.

\section{EXPERIMENTS OF FULL SCALE STEEL FRAME}

Fig. 8 shows the full scale six story steel frame of two spans used in heat tests. This structure was originally elected for the US-Japan cooperative study on the structural behavior under the 
earthquake force. After the completion of their tests, heat tests were made in this structure. The connected part of the columns and the girders was pin joint in one plane and rigid joint in another plane. The composite floor was composed of wide-flange steel girders and light weight reinforced concrete slabs. Four columns were heated separately by the above mentioned furnace which place are shown in Fig.8. No loading was applied. The vertical displacements of the column-girder connected points were measured by dial gauges, and the strain of the steel members were measured by strain gauges.

In all heated tests, local buckling of column occurred, as shown in Photo. 1. The correlation between vertical displacements of top of the column and the mean temperature $T$ is shown in $F i g .9$. The buckling of heated column started when the mean temperature T reached $350 \sim 430^{\circ} \mathrm{C}$. This local buckling occurred at the part where the maximum steel temperature was about $550^{\circ} \mathrm{C}$ same as the model test of $\mathrm{H}-5$.

It is important to attention that after the stop of heating the buckling displacement still continued under the cooling stage. For this shrinkage of column, whole braces from second floor to sixth floor in same plane of heated column buckled remarkably in case of $K-2$.

These phenomenon shows that the fire protection of column is very important for the structural fire safety.
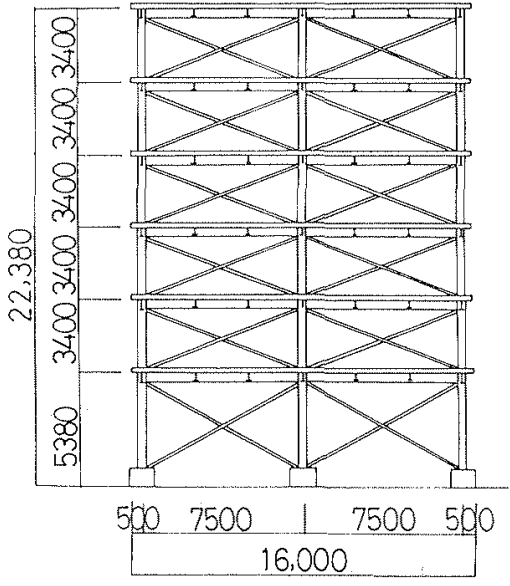

A:HEATED MEMBER

Fig.8 Full scale six story steel frame of two spans
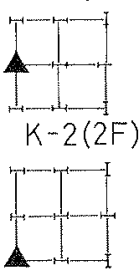

MEMBER
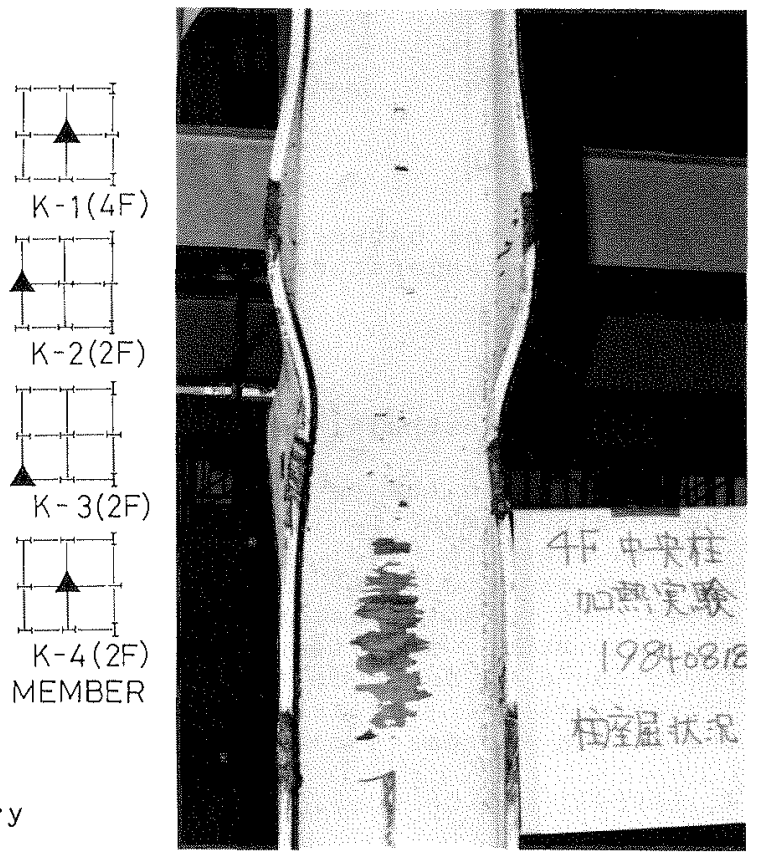

Photo. 1 Local buckling of column ( $\mathrm{K}-1)$ 


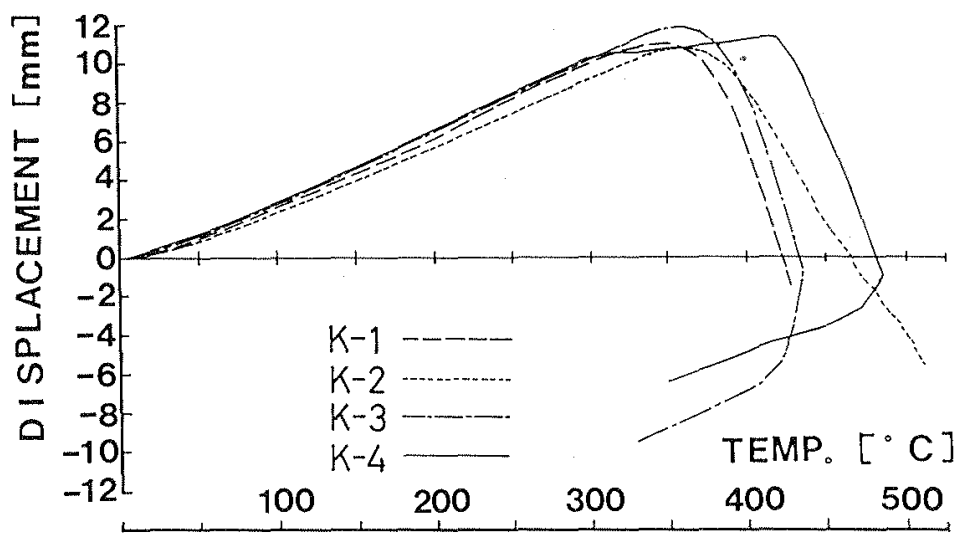

Fig. 9 Correlation between vertical displacement of top of column and mean temperature

\section{CONCLUSIONS}

The following conclusions may be drawn on the basis of experimental results and analysis described above.

It is possible to predict the behavior of a structural steel frame under a fire using the analytical theory on thermal stress inside frame. Under some probable conditions, the structural damage may actually occur in a fire due to large thermal stress.

\section{ACKNOWLEDGMENTS}

The authors wish to acknowledge their considerable debt to Prof. Hikaru Saito. Chiba University, Hideki Uesugi, Assistant of Chiba University, for their support and advice. The analytical method in this paper is based on the theory proposed by prof. Saito. The authors are also grateful to undergraduate students of Science University of Tokyo for fully support of the experiments. The tests in 1982 was financially supported by SECOM Science and Technology Foundation.

\section{REFERENCES}

1. 0.Pettersson, S. Magnusson and J. Thor: Fire Engineering Design of Steel Structures, Swedish Institute of steel Construction, 1976.

2. "European Recommendations for the Calculations of the Fire Resistance of Load Bearing Steel Elements and. Structural Assemblies Exposed to the Standard Fire", ECCS.

3. S.Koike et al., "Experimental Study on Thermal Stress within Structural Steel Work", Fire Science and Technology, Vol.2, No.2, 1982

4. N. Ooyanagi et a 1., "Experimental Study on Thermal Stress within Steel-flames" Fire Science of Technology, Vol.3, No.1, 1983

5. M. Hirota et a 1." "Experimental Study on Structural Behavior of Steel Frames in Building Fire" Fire Science and Technology, 
Vo1.4, No.2, 1984

6. H. Saito, "Behaviour of End Restrained Steel Members under Fire", Bulletin of the Fire Prevention Society of Japan, Vo 1.15, NO.1, Jan., 1966. (in Japanese)

7. H. Saito, "Research on the Thermal Stress of Steel-frame", Prospectus for General Meeting of Architectural Institute of Japan, 1969. (in Japanese)

8. H. Saito, "Fire Safety of Steel-frame", Prospectus for General Meeting of Architectural Institute of Japan, Sept., 1962. (in Japanese)

9. H. Satto, "Thermal Stress of Steel Structure of Tall Buildings in Fire" Fire Science and Technology, Vol.3, No.2, 1983

\section{APPENDIX}

Thermal stress in steel-frame

Theoretical values of the thermal stresses in the frame can be obtained from the formula (1). Supposing that the columns are supported elastically, each coefficient of stiffness for expansion $k$ in the formula (1) is calculated from the formula (2).

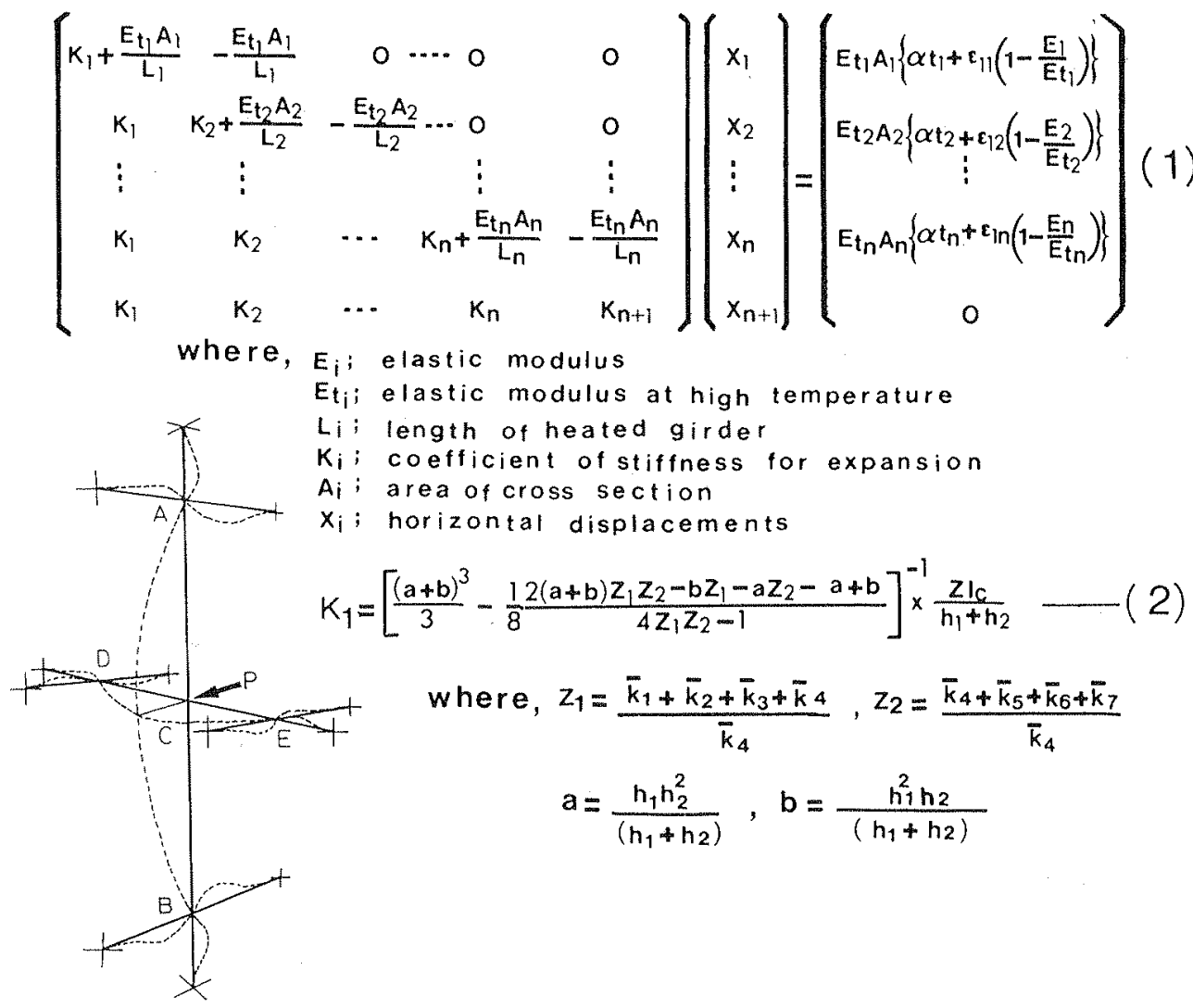

